\section{Reconsideration of Disappearing and Fusing Wrists}

\section{To the Editor:}

Please "bear" with me, but the diagnosis offered by Wegner, et al ${ }^{1}$ is challenged. The wrist alterations in the presented radiologic image ${ }^{1}$ are identical to those noted in Figure 1 presented here, except that in this instance, it has progressed to partial fusion. However, neither this radiograph nor the one in the Wegner, et $a l^{1}$ report actually represents rheumatoid arthritis (RA), and Figure 1 here is that of the manus of a black bear, Ursus americanus OMNH (Oklahoma Museum of Natural History) 33-0-S1. Humans and bears share similar wrist anatomy. Relative sparing of metacarpophalangeal joints and erosive changes in distal interphalangeal joints would be distinctly unusual in RA, but are classic for those of spondyloarthropathy (SpA), especially of the psoriatic variety ${ }^{2}$. While there has been discussion about splitting or lumping peripherally limited erosive disease $^{3}$, the variety of erosive arthritis that occurs in non-human mammals ${ }^{4}$ and specifically in bears ${ }^{5}$ has been clearly identified as SpA. In the case sited herein, syndesmophytes were present and erosive disease was also noted in 1 elbow. There is actually no evidence for occurrence of RA in non-human animals, if the authors considered the alternative diagnosis of SpA and not just ankylosing spondylitis.
BRUCE M. ROTHSCHILD, MD, Department of Medicine, West Virginia University, Morgantown, West Virginia, and Department of Vertebrate Paleontology, Carnegie Museum of Natural History, Pittsburgh,

Pennsylvania, USA. Address correspondence to Dr. B.M. Rothschild, Department of Medicine, West Virginia University College of Medicine, Morgantown, West Virginia 26501, USA. E-mail: spondylair@gmail.com

\section{REFERENCES}

1. Wegner F, Müller-Ladner U, Meier FM. Missing wrists in a patient with rheumatoid arthritis: A matter of compliance. J Rheumatol 2017;44:655

2. Resnick D. Diagnosis of bone and joint disorders, 4 th ed. Philadelphia: Saunders; 2002.

3. Rothschild BM. Two faces of "rheumatoid arthritis": Type A versus type B disease. J Clin Rheumatol 1997;3:334-8.

4. Rothschild BM, Martin LD. Skeletal impact of disease. Albuquerque: New Mexico Museum of Natural History Press; 2006.

5. Rothschild BM, Wang X-M, Cifelli R. Spondyloarthropathy in ursidae: a sexually transmitted disease? Nat Geogr Res Explor 1993;9:382-4.

J Rheumatol 2018;45:6; doi:10.3899/jrheum.171367
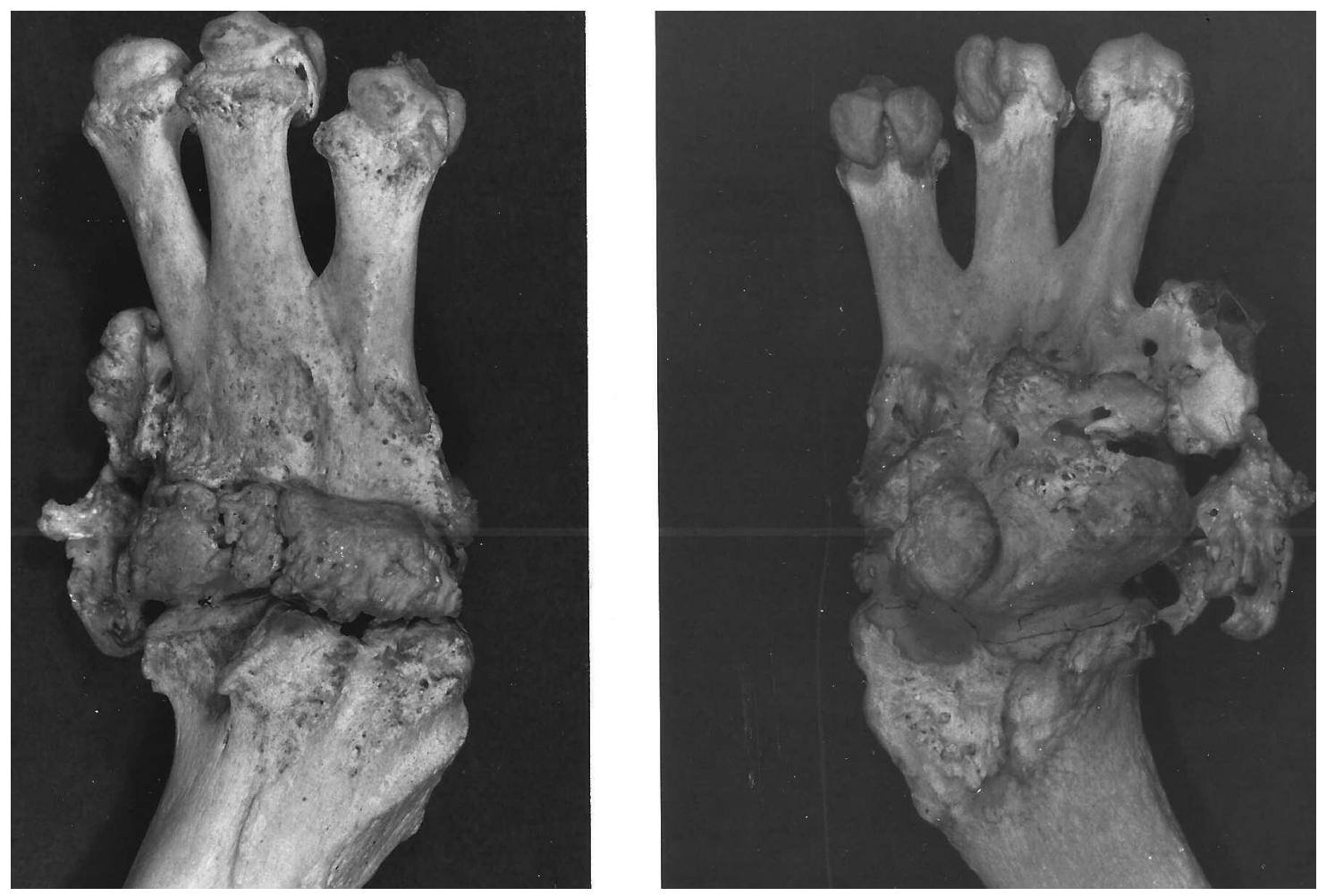

Figure 1. Dorsal (left) and ventral (right) views of right wrist of OMNH 33-0-S1 Ursus americanus. Visible is loss of carpal bones with fusion of residual row. OMNH: Oklahoma Museum of Natural History. 